\title{
Acute respiratory distress syndrome: continuing challenges
}

The death rate from acute respiratory distress syndrome (ARDS) was high during the early days of its documentation [1]. The mortality from ARDS has been decreasing over the years due to several factors including improved supportive care, sedation, nutritional support, treatment of nosocomial pneumonia, and a more evidence-based approach to mechanical ventilation [2]. These interventions require tailoring care targeted toward individual patients.

Sedation and analgesia can be helpful in patients with ARDS, particularly in patients with anxiety and delirium to control agitation, improve tolerance of mechanical ventilation, and decrease oxygen consumption [3]. Some patients require oxygen supplementation and a ventilator [4]. Evidence-based approaches to mechanical ventilation and adjustments of $\mathrm{PaO}_{2} / \mathrm{FiO}_{2}$ according to severity of gas exchange abnormalities are available [5].

Ventilator-associated pneumonia (VAP) is a frequent complication of ARDS. Clinical guidelines to care for VAP in ARDS are available [6].

The paper by Sanguanswong and Kongpolprom published in this volume [7] suggests that even in a university hospital, the 28-day mortality of ARDS in patients admitted to the intensive care unit (ICU) is high. It was also found that the average tidal volume and fluid balance are greater than the protective limits. Data elsewhere suggest that a conservative fluid management strategy that aims to minimize or eliminate positive fluid balance is desirable. Conservation of fluid management in adults with respiratory distress syndrome can improve cognitive outcomes and long-term neuropsychological function in survivors of acute lung injury [8].

Thus, continuing challenges exist and must be addressed to achieve an improvement in ARDS outcomes. Evidence-based approaches particularly from collaborative studies are desirable.

Many causes of ARDS have been documented but only a few common causes account for most cases of ARDS in the medical ICU such as pneumonia, sepsis, and aspiration [9]. Early identification and early treatment of cases before the need for ICU admission remain a challenge and would require a close collaboration between healthcare providers and hospitalized patients.

\section{References}

[1] Ashbaugh DG, Bigelow DB, Petty TL, Levine BE. Acute respiratory distress in adults. Lancet. 1967; 2:319.

[2] Erickson SE, Martin GS, Davis JL, Matthay MA, Eisner MD, NIH NHLBI. ARDS network recent trends in acute lung injury mortality: 1996-2005. Crit Care Med. 2009; 37:1574.

[3] Barr J, Fraser GL, Puntillo K, Ely EW, Gélinas C, Dasta JF, et al. Clinical practice guidelines for the management of pain, agitation, and delirium in adult patients in the intensive care unit. Crit Care Med. 2013; 41:263.

[4] Hasleton PS. Adult respiratory distress syndrome. In: Hasleton PS, editor. Spencer's pathology of the lung. New York: McGraw Hill; 1996, p. 375.

[5] Schoenfeld D, Thompson BT, Wheeler A Brower RG, Matthay MA, Morris A. Ventilation with lower tidal volumes as compared with traditional tidal volumes for acute lung injury and the acute respiratory distress syndrome. Acute Respiratory Distress Syndrome Network. N Engl J Med. 2000; 342:1301.

[6] Dalhoff K, Abele-Horn M, Andreas S, Bauer T, von Baum H, Deja M, et al. Epidemiology, diagnosis and treatment of adult patients with nosocomial pneumonia - S3 guideline of the German Society for anaesthesiology and intensive care medicine, the German society for infectious diseases, the German society for hygiene and microbiology, the German respiratory society and the Paul-Ehrlich-society for

*Correspondence to: Editorial Office of Asian Biomedicine, Faculty of Medicine, Chulalongkorn University, Bangkok 10330, Thailand, e-mail: abmjournal@chula.ac.th

כ Open Access. ๑ 2018 Editorial Office of Asian Biomedicine, published by Sciendo. (⿶) BY-NC-ND This work is licensed under the Creative Commons Attribution NonCommercial-NoDerivatives 4.0 License. 
chemotherapy, the German radiological society and the society for virology. Pneumologie. 2018; 72:15-63. [in German, English abstract]

[7] Sanguanswong N, Kongpolprom N. Clinical outcomes of acute respiratory distress syndrome in a University Hospital. Asian Biomed (Res Rev News). 2018; 12:263-271.

[8] Mikkelsen ME, Christie JD, Lanken PN, Biester RC, Thompson BT, Bellamy SL, et al. The adult respiratory distress syndrome cognitive outcomes study: long-term neuropsychological function in survivors of acute lung injury. Am J Respir Crit Care Med. 2012; 185:1307.

[9] Hudson LD, Milberg JA, Anardi D, Maunder RJ. Clinical risks for development of the acute respiratory distress syndrome. Am J Respir Crit Care Med. 1995; 151:293. 